\title{
A configuração funcional da argumentação prática: uma releitura do layout de Fairclough \& Fairclough (2012)
}

\section{Paulo Roberto Gonçalves-Segundo}

Docente da Universidade de São Paulo (USP), Brasil. paulosegundo@usp.br

Resumo: O objetivo deste artigo é discutir uma releitura do layout de argumentos proposto por Fairclough \& Fairclough (2012) para a análise de textos de visada argumentativa prática. Em primeiro lugar, colocaremos em relevo a discussão sobre dissenso, situando o layout como um dispositivo de configuração funcional que estrutura uma resposta a um problema prático, que pode ser orientado a alternativas de ação ou às motivações para a ação. Em segundo lugar, reconceptualizamos a noção de Circunstâncias a partir de um diálogo com o esquema imagético de FORÇA (TALMY, 2000), de forma a gerar uma nova tipologia que amplia o potencial descritivo do dispositivo. Em terceiro lugar, propomos um conjunto de seis critérios relevantes para a descrição e avaliação de argumentos práticos: trata-se dos critérios de eficácia, viabilidade, eficiência, inofensividade, beneficiamento e respeito aos Valores. Finalizamos o artigo com a análise de um tweet sequencial da edutuber Nilce Moretto, mostrando a validade da discussão teórica e da releitura de categorias e critérios discutidos no artigo.

Palavras-chave: Argumentação prática. Avaliação. Configuração functional. Dinâmica de Forças.

\begin{abstract}
This paper aims to discuss a reframing of Fairclough and Fairclough's (2012) layout of arguments for the analysis of practical reasoning in situated argumentative practices. First, we highlight the importance of dissension to conceptualize the layout as a model of functional configuration that structures an answer to a practical problem, which may be oriented towards alternatives of action or towards motivations for action. Second, we reframe the notion of Circumstances through a dialogue with the FORCE image schema (TALMY, 2000), in order to propose a typology that refines the descriptive potential of the layout. Third, we systematize a series of six relevant criteria to describe and evaluate practical arguments, namely the efficacy, the viability, the efficiency, the harmlessness, the beneficiation and the respect criteria. We end the paper with the analysis of a sequential tweet, authored by the edutuber Nilce Moretoo, showing the pertinence of the theoretical discussion and of the reframing of categories and criteria discussed throughout the article.
\end{abstract}

Keywords: Practical argument. Evaluation. Functional Configuration. Force Dynamics. 


\section{Introdução}

Já é tradicional, no âmbito das diversas teorias sobre argumentação, a diferenciação entre duas orientações gerais para a atividade argumentativa: a orientação para o crer e a orientação para o fazer/decidir. Tais distinções funcionais levaram pesquisadores a propor diferentes layouts de funcionamento argumentativo que buscassem dar conta das especificidades de cada uma dessas orientações. A Lógica Informal, em particular, deteve-se sobre essas especificidades, conforme podemos verificar em Walton (1990, 2013) e Macagno \& Walton (2019).

Neste trabalho, buscaremos explorar - teórica e analiticamente, agregando expansões, rearranjos e revisões - o layout de argumentação prática proposto por Fairclough \& Fairclough (2012), originalmente orientado ao estudo de interações deliberativas políticas, de forma a discutir sua aplicação para textos monologais de visada argumentativa prática, em que se busca persuadir um auditório particular a decidir favorável ou desfavoravelmente a alguma Proposta de Ação (independentemente da efetivação material da ação propriamente dita). Nesse processo, debateremos suas limitações e seus potenciais, especialmente em termos das categorias mobilizadas para a descrição da rede de argumentos que sustenta a Proposta de Ação, considerando aspectos ligados tanto à consistência quanto à adesão.

Nesse sentido, organizamos o artigo da seguinte forma: inicialmente, apresentaremos nossa concepção de argumentação, ligada ao modelo multidisciplinar e multidimensional de análise argumentativa que temos desenvolvido (GONÇALVES-SEGUNDO, 2018; no prelo), buscando dar conta dos aspectos justificatório e comunicativo da argumentação; posteriormente, discutiremos criticamente o funcionamento dos movimentos argumentativos de natureza prática a partir de Fairclough \& Fairclough (2012); por fim, ilustraremos a pertinência da nossa releitura do layout a partir da análise de um tweet sequencial da edutuber Nilce Morreto que incita a participação de pesquisadores em espaços virtuais para combater a cultura anticientífica e anti-intelectualista que ela constrói como problemática no Brasil contemporâneo. 
2. Pensando a argumentação em perspectiva multidisciplinar e multidimensional

Assumimos com Leitão (2012) que a atividade argumentativa é complexa e pode ser caracterizada como discursiva, dialógica, social, dialética, cognitiva e epistêmica. Por conta disso, parece-nos relevante que ela seja estudada em termos tanto do seu aspecto justificatório quanto comunicativo, como bem defende Bermejo-Luque (2011). Logo, podemos propor que argumentar pressupõe: (i) a mobilização de sistemas cognitivos que viabilizam diferentes formas de raciocínio e de perspectivação; (ii) a ancoragem em regimes discursivos que ratificam modos sócio-historicamente consolidados de tomar posição, de convencer e de persuadir; (iii) a instanciação estratégica de procedimentos multimodais - dentre os quais se destacam a linguagem verbal e visual - para sua materialização textual. Por conseguinte, uma análise argumentativa envolve, em nossa visão, considerar aportes de três campos complementares à Teoria da Argumentação propriamente dita: a Linguística, as Ciências Cognitivas e os Estudos Discursivos ${ }^{1}$.

Inspirados em Niño \& Marrero (2015), entendemos que uma atividade de tamanha complexidade não pode ser reduzida a uma visão monofuncional. Nesse sentido, concebemos que a argumentação pode estar orientada ao convencimento, à persuasão ou à preservação ideológica.

Compreendemos por convencimento, neste trabalho, o efeito perlocutório de aderir, ainda que localmente e/ou em graus, a certas concepções da realidade em consequência de considerá-las consistentes e/ou razoáveis, tendo por base a força variável do elo entre Dados e Alegação, por meio da Garantia, considerando a adequação de possíveis Refutações e a confiabilidade das Bases. Cognitivamente, o convencimento está atrelado a processos de formação ou revisão de crenças, bem como de rejeição de crenças anteriores; trata-se do domínio da argumentação epistêmica. Para a análise dessa função, concebemos como útil o dispositivo desenvolvido por

\footnotetext{
${ }^{1}$ Tendo em vista o arcabouço multidisciplinar, diferentes terminologias serão empregadas para se referir aos/às oradores/as. Utilizaremos, alternadamente, conceptualizador/a, voz autoral e Proponente para tratarmos daquele/a que argumenta. A variação dependerá da tônica da análise no momento: se cognitiva, o termo conceptualizador/a será preferido; se discursiva, voz autoral; se argumentativa - no sentido de abarcar a voz, ou o conjunto de vozes, que defende uma determinada Alegação ou Proposta de Ação -, Proponente. Para um detalhamento sobre tais noções, consultar, respectivamente, Langacker (2008) ou Gonçalves-Segundo (2017b); Fairclough (2003); e Plantin (2008).
} 
Toulmin (2006 [1958]) e por Toulmin, Rieke \& Janik (1984 [1978]), considerando as releituras que permitem ampliar seu potencial descritivo em termos justificatórios e comunicativos (VERHEIJ, 2006; SLOB, 2006; LANGSDORF, 2011; GONÇALVES-SEGUNDO, 2016).

Definimos persuasão como o efeito perlocutório de decidir favorável ou desfavoravelmente a projetos de mudança no curso da realidade - e não da concepção de realidade, como ocorre no convencimento. Assim, a consistência da argumentação está ligada à força do elo entre Valores, Consequências e Circunstâncias que envolvem a Ação proposta no que tange aos Objetivos colocados à deliberação. Em termos cognitivos, a persuasão está ligada à defensibilidade de crenças e consiste em meta privilegiada da argumentação prática. Para o estudo dessa função, consideramos particularmente útil o trabalho de Fairclough \& Fairclough (2012).

Por fim, entendemos como preservação ideológica o efeito perlocutório de confirmar/reforçar dada concepção de realidade, pela apresentação tanto de Dados e Alegações que já são compartilhados e acordados entre os membros do endogrupo (nós), quanto de Refutações a argumentos que já são considerados inválidos pelo mesmo grupo. Esse processo está ligado, portanto, à manutenção dos sistemas de crença dos conceptualizadores, o que pode gerar efeitos positivos na construção da identificação, mas efeitos negativos em termos de enviesamento. Trata-se de um campo que ainda carece de estudos sistemáticos para a consolidação de uma proposta de configuração funcional.

Além de múltiplas funções, podemos estudar a argumentação a partir de um conjunto amplo de dimensões, a fim de que possamos fazer jus aos inúmeros fatores implicados no seu funcionamento.

Em primeiro lugar, destacamos a dimensão da configuração funcional, que diz respeito aos scripts de operacionalização dos movimentos argumentativos. Tal dimensão está mais diretamente associada ao aspecto justificatório (ou lógico) da argumentação e, portanto, aos modos de organização do raciocínio argumentativo textualizado ou inferível, ainda que seja possível, por meio dela, dar conta do dissenso e do dialogismo inscritos na argumentação, concernentes ao aspecto comunicativo (ou retórico). Pelo estudo dessa dimensão, podemos depreender o papel das distintas 
proposições - derivadas de enunciados - na defesa de Alegações e de Propostas de Ação, por mais que tenhamos que reduzir, em maior ou menor grau, suas marcas enunciativas para compreendermos o raciocínio efetuado. É no âmbito dessa dimensão que se localizam os layouts de Toulmin ([2006]1958) e Fairclough \& Fairclough (2012).

Em segundo lugar, temos a dimensão da macroestrutura, que abrange 0 estudo das distintas formas pelas quais os argumentos podem ser combinados na defesa de Alegações ou de Propostas de Ação. Trata-se de dimensão intimamente ligada à configuração funcional, de tal modo que é impossível que investiguemos uma delas sem recorrer à outra. Caso façamos uma analogia cara à Linguística, a configuração funcional está mais para o paradigma, ao passo que a macroestrutura está mais para o sintagma; ambas precisam, portanto, ser analisadas conjuntamente. Podemos observar propostas relevantes de macoestruturação em Freeman (2011) e van Eemeren, Houtlosser \& Snoeck-Henkemans (2007).

Em terceiro lugar, a dimensão da esquematização envolve os tipos de raciocínio e as estratégias empregadas para conferir consistência e promover adesão $^{2}$ às Alegações e às Propostas de Ação. A literatura conta com variadas tipologias, orientadas por critérios e finalidades diversas, para dar conta das diferentes possibilidades de raciocínio e seu potencial de convencimento ou de persuasão. São muito influentes as tipologias de Perelman \& OlbrechtsTyteca (2002[1958]), da Lógica Informal (Walton, Reed \& Macagno, 2008) e da Pragmadialética (van Eemeren, Houtlosser \& Snoeck-Henkemans, 2007).

Em quarto lugar, a dimensão da ancoragem socioafetiva abarca o estudo da construção da autoridade, da credibilidade e da atração do orador assim como do papel dos valores e das emoções do auditório nos processos de convencimento, persuasão e/ou preservação ideológica. Liga-se, portanto, à toda a tradição de estudos sobre o ethos e o pathos. Ressaltamos, dentre os vários trabalhos, as propostas de Maingueneau (2005) e de Amossy (2018).

\footnotetext{
2 Reservamos o termo consistência para tratar do aspecto justificatório da argumentação, usualmente abordado por paradigmas que privilegiam o raciocínio e a argumentação como produto, como a Lógica Informal (ver, por exemplo, BLAIR \& JOHNSON, 2017 [2000]; WALTON, 2013; dentre outros), e o termo adesão para o aspecto comunicativo, normalmente estudado pelos paradigmas que privilegiam a eficácia e a argumentação como processo, como a Retórica (ver, por exemplo, PERELMAN \& OLBRECHTS-TYTECA, 2002 [1958]; PLANTIN, 2008). É claro que há paradigmas que tentam combinar, em maior ou menor grau, as duas tradições, como a Pragmadialética (van EEMEREN, 2018).
} 
Por fim, a dimensão da orientação argumentativa ou perspectivação concerne ao papel que os recursos léxico-gramaticais e imagéticos exercem no processo de gerar consistência e promover adesão. A análise dessa dimensão é relevante, na medida em que recupera os aspectos enunciativos que a configuração funcional pode ocultar e destaca o papel do linguístico (e do imagético) na construção do movimento argumentativo. É também no âmbito dessa dimensão que a análise das figuras se processa. Para esse estudo, valemo-nos especialmente de teorizações linguísticas centradas na significação, como a Linguística Sistêmico-Funcional (Halliday, 2004; Martin \& White, 2005) e a Linguística Cognitiva (Hart, 2014; Gonçalves-Segundo, 2017b) aplicadas ao texto e ao discurso.

Isso posto, passamos à discussão sobre o layout de configuração funcional da argumentação prática de Fairclough \& Fairclough (2012).

3. A configuração funcional da argumentação prática: expandindo o layout de Fairclough \& Fairclough (2012)

Fairclough \& Fairclough (2012) propõem um modelo de argumentação prática orientado a explicar o funcionamento de argumentações voltadas à defesa de Propostas de Ação em contextos deliberativos, nos quais diferentes alternativas de ação são examinadas e discutidas com o objetivo de que uma decisão seja tomada. O modelo também parece ser aplicável a outras práticas argumentativas, como as verificadas em editoriais ou artigos de opinião, ou mesmo a entrevistas ou debates, conforme mostraremos na análise do tweet sequencial de Nilce Moretto.

Enquanto, na argumentação epistêmica, o movimento argumentativo é direcionado à Alegação, na argumentação prática, o movimento argumentativo é direcionado à Proposta de Ação. Tal proposta é sustentada a partir de uma rede complexa de constituintes orientada para sua legitimação e para a deslegitimação de Contra-Propostas. Tais constituintes são: os Objetivos, as Circunstâncias, os Valores, as Consequências da ação e a relação Meio-Fim.

De forma sintética, podemos afirmar que, a partir de uma dada leitura das Circunstâncias vigentes, constrói-se um problema que requisita solução. Tal solução consiste em uma Proposta de Ação cujo Objetivo, em geral, é 


\section{$\mathrm{EI} \square \mathrm{dA}$}

resolver, em maior ou menor grau, o problema, ou seja, superar o estado de coisas presente que é indesejável, inaceitável ou aprimorável. Todos esses componentes estão, por sua vez, submetidos aos Valores que atravessam os discursos aos quais o orador se filia, delimitando as formas de conceber a realidade presente, o imaginário referente ao futuro visado e a pertinência da Proposta de Ação a ser implementada. Consequências positivas ou negativas projetadas a partir da efetivação da Proposta de Ação são construídas no sentido de ampliar ou reduzir-lhe a adesão. A figura abaixo, adaptada de Fairclough \& Fairclough (2012) e de Sousa (2018), apresenta o layout original:

Figura 1 - Layout de argumentação prática

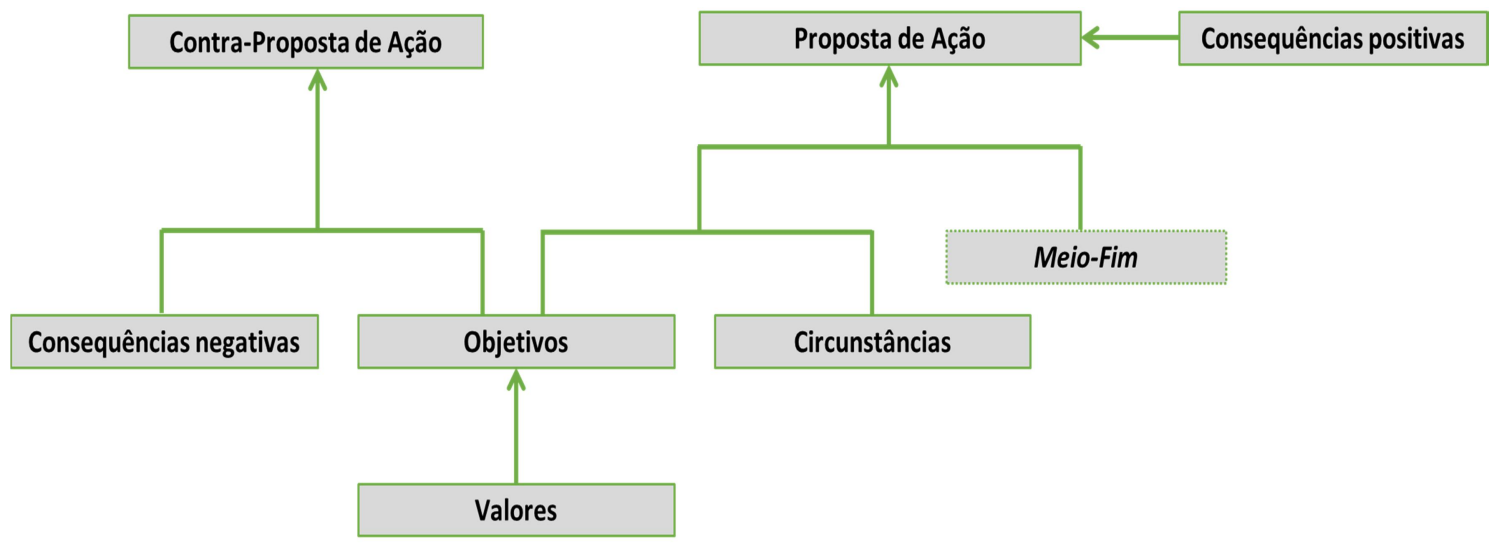

Fonte: Adaptado de Fairclough \& Fairclough (2012) e Sousa (2018)

Propostas de Ação são, em geral, instrumentos ou meios para se alcançar um dado Objetivo ou fim. Linguisticamente, defendemos que elas podem se manifestar, tipicamente, por meio dos seguintes recursos: (i) julgamentos de propriedade (Martin \& White, 2005), que indicam se as propostas são corretas ou erradas, boas ou ruins, pertinentes ou não; (ii) marcadores deônticos, que assinalam dever, obrigação ou necessidade, como os verbos dever, ter que; (iii) marcadores volitivos, que indicam desejo, vontade; ou (iv) imperativos.

Em geral, uma proposta é construída contra um fundo de outras Propostas de Ação (Contra-Propostas), que consistem em alternativas para o alcance do Objetivo; em outros termos, em alternativas de solução para um problema prático. 
Dialogando com a tradição francófona, em especial com autores como Grácio (2010) e Plantin (2008), entendemos que a argumentação se funda no dissenso e que, emerge, portanto, de situações interativas nas quais julgamos razoável ponderar diferentes respostas a uma questão argumentativa. Questões argumentativas são resultado do confronto entre perspectivas conforme bem assinala Grácio (2010) -, advindas da filiação das vozes autorais a distintas discursividades.

No que tange à argumentação prática, defendemos que haja, pelo menos, dois grandes enquadramentos ${ }^{3}$ : (i) argumentações práticas cuja problemática é sustentada por um acordo prévio quanto a Circunstâncias e a Objetivos; e (ii) argumentações práticas cuja problemática é oriunda de um desacordo sobre Circunstâncias e Objetivos.

No primeiro enquadramento, há um acordo prévio sobre os Objetivos a serem perseguidos e, portanto, algum nível de consenso sobre o estado-decoisas futuro visado, de forma que o objeto de dissenso consiste nas próprias alternativas de ação a serem efetivadas para que o estado visado se torne efetivo. Nesses casos, a questão argumentativa poderia ser expressa da seguinte forma: “O que se deve fazer para alcançar o Objetivo?". Nesse sentido, ao compreendermos, na esteira de Fairclough \& Fairclough (2012, p. 43, tradução nossa), que Objetivos consistem em "estados-de-coisa futuros gerados por alguma fonte de normatividade, especificada na premissa de Valor" e que Circunstâncias equivalem aos estados-de coisas presentes que são "inerentemente vistos como um problema a ser resolvido, sendo portanto negativamente avaliados do ponto de vista dos Objetivos do agente" (Fairclough \& Fairclough, 2012, p. 46, tradução nossa, itálico dos autores), a raiz da emergência da argumentação prática se encontra na discrepância entre uma leitura discursivamente perspectivada de um estado-de coisas presente, concebido como indesejável, inaceitável ou aprimorável, e um estado-de-coisas futuro visado, que concretiza um projeto de mudança da realidade que se coaduna aos Valores de um discurso ao qual os participantes da interação se filiam. Dado esse acordo entre a avaliação negativa do presente e a avaliação positiva do futuro visado, a discussão fica centrada nos distintos projetos de mudança a serem implementados e no seu potencial de

\footnotetext{
3 Acreditamos ser possível que outros enquadramentos sejam pertinentes. Por ora, contudo, restringir-nos-emos a esses dois.
} 
alcançar os Objetivos. Nesse sentido, a relação Meio-Fim - que atua de forma análoga a uma Garantia toulminiana (2006[1958]), na medida em que consiste em um raciocínio, em geral, implícito, discursivamente ancorado, que licencia a projeção de que uma dada Proposta de Ação, de fato, levará ao estado-decoisas futuro pretendido - encontra-se no cerne do debate e, portanto, apresenta maior potencial de se tornar alvo de refutação. Denominamos tal tipo de dissenso como um problema prático orientado a alternativas de ação.

O segundo enquadramento envolve a discussão sobre a implementação de uma Proposta de Ação, ou seja, de um projeto de mudança de realidade que se encontra pautado e será debatido à luz tanto de sua pertinência, produtividade, compatibilidade e efeitos em relação aos Objetivos e Valores dos grupos envolvidos na interação, o que inclui os modos pelos quais eles hierarquizam suas prioridades, quanto de sua necessidade, na medida em que pode, inclusive, haver desacordo quanto à leitura das Circunstâncias, ou seja, da avaliação do estado-de-coisas presente. Nesse caso, a questão poderia ser expressa do seguinte modo: “Tal Proposta de Ação deve ser implementada?". Nesse caso, a relação Meio-Fim não é um aspecto central da discussão, visto que não se está debatendo se a Proposta de Ação é o melhor meio para se atingir os Objetivos, mas se está discutindo acerca de tal projeto ser necessário ou desejável, uma vez que não há acordo sobre a avaliação negativa do presente, elemento crucial para a emergência de um problema prático, ou mesmo sobre a natureza do estado-de-coisa futuro que se visa alcançar. Nesse tipo de dissenso, o que se coloca é uma resposta fechada "sim" ou "não" - orientada à Proposta em pauta. Denominamos tal tipo de dissenso como um problema prático orientado às motivações para ação.

Embora a discussão realizada anteriormente tenha enfatizado as distinções, é importante ressaltarmos que, em ambas as situações, o dissenso encontra-se orientado a projetos de mudança/intervenção de realidade; além disso, trata-se de problemas que envolvem alternativas: no primeiro caso, o número de alternativas não é, em princípio, definível, e a interação volta-se não só à defesa de uma proposta, como também à invalidação de outras, de forma que, muitas vezes, a adesão a uma delas resulta de uma resistência maior à crítica, conforme já apontam Fairclough \& Fairclough (2012); no segundo caso, o número de alternativas é reduzido a dois, na medida em que o dissenso se resume a aprovar ou barrar o projeto em pauta. 
Toda essa dinâmica nos leva à mesma conclusão a que Fairclough \& Fairclough (2012) chegaram: a de que a argumentação prática consiste, em termos do aspecto justificatório da argumentação, em uma modalidade de racionalidade condutiva. Nesse tipo de racionalidade, os participantes precisam pesar, cognitivamente, os prós e os contras relativos a cada Proposta de Ação sugerida, levando em consideração tanto o tipo de problema quanto uma série de critérios, dentre os quais propomos ser relevantes:

a) eficácia da Proposta de Ação; em outros termos, a sua capacidade de gerar o estado-de-coisas futuro expresso nos Objetivos;

b) viabilidade da Proposta, ou seja, o potencial presente de efetivá-la. Em geral, esse critério está associado à avaliação sobre a disponibilidade de recursos materiais e a competência dos atores sociais para implementar a Proposta;

c) eficiência da Proposta, que decorre de sua viabilidade, diz respeito à quantidade projetada de recursos a serem empregados e/ou ao grau projetado de esforço a ser desprendido para efetivar a Proposta até atingir o Objetivo;

d) inofensividade da Proposta; em outros termos, o potencial de sua efetivação gerar consequências negativas e novos problemas avaliados como indesejáveis ou inaceitáveis pelos grupos envolvidos no debate;

e) beneficiamento resultante da Proposta, ou seja, seu potencial de gerar consequências positivas tanto no sentido de constituírem etapas para o alcance dos Objetivos quanto no sentido de trazerem benefícios não diretamente associados ao estado futuro visado, mas que ecoam de modo convergente com os Valores de uma dada filiação discursiva.

Esses dois últimos critérios de avaliação de argumentos de natureza prática estão diretamente associados à tradicional discussão, no âmbito da Retórica, acerca do dito argumento ou esquema pragmático. Segundo Perelman e Olbrechts-Tyteca (2002[1958], p. 303), “o argumento pragmático, que permite apreciar uma coisa consoante suas consequências, presentes ou 
futuras, tem uma importância direta para a ação". Ele só pode se desenvolver - segundo os autores - se houver um acordo sobre os valores das consequências, em geral, associados ao sucesso do que se objetiva. Logo, se o Oponente projeta Consequências Negativas que ferem algum Valor considerado relevante para o grupo ou ainda trazem novos problemas, o apoio a uma dada Proposta tende a diminuir; ocorre o inverso se Consequências Positivas são projetadas discursivamente. Muitas vezes, a decisão acaba sendo tomada com base na alternativa de ação que mais resistiu a críticas.

f) o (des)respeito aos Valores, isto é, a avaliação da compatibilidade do projeto de mudança proposto em relação aos compromissos éticos e morais de um dado grupo. Costuma envolver avaliações de propriedade e honestidade (Martin \& White, 2005).

Os Valores, segundo a elaboração de Fairclough \& Fairclough (2012), dizem respeito às preocupações factuais dos atores sociais ou aos compromissos que eles assumem como parte da ordem do discurso da instituição à qual estão vinculados. Nesse sentido, não devemos igualar Valores a desejos individuais, ainda que eles possam coincidir ${ }^{4}$.

\footnotetext{
${ }^{4}$ Trata-se de diferenciação importante, na medida em que os Valores podem estar associados a posicionamentos, crenças e atitudes inculcadas tanto em identidades estruturalmente constrangidas - o que abrange identidades sociais que são relevantes independentemente da rede de práticas, gerando impactos nas distintas esferas, não raro reveladas por distintas formas de acesso, participação e inclusão/exclusão, como gênero, sexualidade, raça, idade, classe socioeconômica -, quanto em identidades reguladas pelo sistema posição-prática (MATEUS \& RESENDE, 2015) - o que abarca identidades sociais relativas a funções que os atores sociais ocupam em distintas esferas e nas práticas sociais a elas subordinadas. Nesse sentido, enquanto as primeiras atravessam o nosso fazer de forma mais geral, as últimas tendem a se manifestar em nossa agência localizada. Contudo, cada uma dessas identidades revela processos de inculcação (FAIRCLOUGH, 2003) de discursividades variadas, que ora convergem, ora divergem, tanto na relação entre as duas categorias de identidade quanto no âmbito de cada uma delas. Assim, é possível que compromissos de dever de uma posição na prática se choquem com valores advindos de nossa identificação de raça ou de gênero, por exemplo, o que está diretamente associado às hierarquias de valores que emergem na argumentação prática. Esses choques podem ocorrer tanto no âmbito do discurso de uma única voz autoral, quanto no âmbito do confronto entre interlocutores distintos. Muitas vezes, na argumentação prática, é relevante compreender de que posição se fala quando são construídos dados Objetivos e Propostas: como mãe, como gerente, como branca, como brasileira, dentre outras possibilidades que podem ser passíveis de atribuição a um mesmo ator social.
} 
A partir desse enquadramento, é possível depreender que os Valores ocupam três funções fundamentais: (i) a de restringir o conjunto de ações que pode ser proposto; (ii) a de delimitar o Objetivo que deve ser alcançado; e (iii) a de sustentar a seleção e a descrição das Circunstâncias que caracterizam o estado-de-coisas indesejável ou inaceitável, a partir do qual o problema prático se origina. Como Valores se constituem em aspectos centrais de discursos, podemos concluir que a construção de Circunstâncias emerge de um processo de perspectivação sustentado pelos discursos aos quais as vozes autorais se filiam.

É no componente circunstancial, contudo, que acreditamos que o layout de Fairclough \& Fairclough (2012) pode ser detalhado, com o objetivo de ampliar seu potencial descritivo e explicativo em termos do processo condutivo que envolve a argumentação prática. Considerando que os autores não só veem as circunstâncias como o estado-de-coisas presente avaliado negativamente, mas também como o contexto de ação do Agente - no caso, aqueles implicados na decisão e/ou na realização da Proposta -, que envolve fatos institucionais e sociais que regulam as possibilidades de ação (cf. Fairclough \& Fairclough, 2012, p. 47-8), podemos, inspirados no esquema imagético ${ }^{5}$ de FORÇA, tal qual discutido por Talmy (2000), Oakley (2005) e Gonçalves-Segundo (2015, 2017a), propor uma tipologia de Circunstâncias que defendemos ser útil para o refinamento do modelo ${ }^{6}$.

Talmy (2000), em seu modelo de Dinâmica de Forças, ligado a uma concepção corporeada de cognição aplicada à linguagem, propõe que nossa experiência com forças, pressão e movimentação pode ser metaforizada para outros domínios de experiência, como o psicológico, o social e até mesmo o argumentativo, permitindo-nos compreender realidades complexas a partir desse conhecimento empírico mais concreto.

\footnotetext{
${ }^{5}$ Lakoff (1987, p. 14) concebe esquema imagético como "um padrão dinâmico e recorrente de interação perceptual e programação motora que dá coerência e estrutura à experiência humana"; nesse sentido, constitui-se em "matéria-prima" para a formação de frames. Esses, por sua vez, consistem em redes conceituais que organizam o conhecimento, proporcionando-nos competência para interpretar situações e reagir adequadamente em face das distintas práticas em que nos envolvemos (CIENKI, 2007).

${ }^{6}$ A análise dos dados, a ser realizada na próxima seção, mostrará esse potencial claramente. Para uma compreensão mais detida do funcionamento da Dinâmica de Forças na Gramática do Português, ver Gonçalves-Segundo (2015) e Moura (2012); para aplicações discursivas, ver Hart (2014), Oakley (2005) e Gonçalves-Segundo (2015, 2017b); para aplicações na argumentação, ver Oakley (2005) e Gonçalves-Segundo (2017a).
} 
Nesse modelo, há basicamente quatro elementos constitutivos: (i) as entidades de força; (ii) a tendência intrínseca de ação ou repouso dessas forças; (iii) o equilíbrio dessas forças; e (iv) a resultante de sua interação. Conforme Gonçalves-Segundo (2017a, p. 203),

As entidades de força consistem no Agonista $\left(\mathrm{AGO}^{7}\right)$ e no Antagonista (ANT), noções conceptuais que podem ser realizadas por distintas funções sintáticas e papéis temáticos na estrutura oracional ${ }^{8}$. O AGO consiste na entidade cuja tendência de força - ação ou repouso - se encontra em foco. Tal tendência será mantida a menos que a ação de um ANT possa revertê-la. Assim, o ANT consiste na entidade que entra em oposição ao AGo, podendo ou não impor sua tendência em relação a ele, a depender do equilíbrio projetado, ou seja, de ser mais forte ou mais fraco que esse.

O Quadro 1 exemplifica, de forma sucinta, a aplicação do esquema imagético a complexos oracionais:

\section{Quadro 1 - Padrões de interação de força9}

\begin{tabular}{|c|c|c|}
\hline CAUSAÇÃO & $\begin{array}{l}\text { AGO: a quadrilha (que tende a não roubar } R \$ 1 \\
\text { bilhão) } \\
\text { ANT: a polícia } \\
\text { RES: roubar R\$ } 1 \text { bilhão } \\
\text { ANT, que tende à ação e é mais forte, impõe sua } \\
\text { tendência ao AGO, fraco e em repouso, } \\
\text { causando a resultante roubar } R \$ 1 \text { bilhão. }\end{array}$ & $\begin{array}{l}\text { “[...] a polícia } \\
\text { fez a quadrilha } \\
\text { roubar R\$1 } \\
\text { bilhão” }\end{array}$ \\
\hline BLOQUEIO & $\begin{array}{l}\text { AGO: a quadrilha (que tende a roubar } \mathrm{R} \$ 1 \text { bilhão) } \\
\text { ANT: a polícia } \\
\text { RES: não roubar R\$ } 1 \text { bilhão } \\
\text { ANT, que tende ao repouso e é mais forte, } \\
\text { impõe sua tendência ao AGo, fraco e com } \\
\text { tendência à ação, bloqueando a resultante } \\
\text { roubar } R \$ 1 \text { bilhão. }\end{array}$ & $\begin{array}{l}\text { “[...] a polícia } \\
\text { impediu que } \\
\text { quadrilha } \\
\text { roubasse R\$1 } \\
\text { bilhão" }\end{array}$ \\
\hline
\end{tabular}

\footnotetext{
${ }^{7}$ Por convenção da área de Linguística Cognitiva, esquemas imagéticos e seus componentes são redigidos em VERSALETE (SMALL CAPS).

${ }^{8}$ Em alguns padrões, como é o caso do DESENGAJAMENTO, há uma terceira entidade: o Agente (AGT) que remove o Antagonista.

9 Todos os complexos oracionais que compõem o quadro resultam de manipulações realizadas para efeitos didáticos do segmento sublinhado a seguir, extraído do título de uma nota do Portal G1: No Fantástico: como a polícia impediu que quadrilha roubasse $R \$ 1$ bilhão.
} 


\begin{tabular}{|c|c|c|}
\hline DESENGAJAMENTO & $\begin{array}{l}\text { AGO: a quadrilha (que tende a roubar } R \$ 1 \text { bilhão) } \\
\text { ANT: não especificado } \\
\text { AGT: a polícia } \\
\text { RES: roubar R\$ } 1 \text { bilhão } \\
\text { ANT - que tende ao repouso e é mais forte que } \\
\text { O AGO, que tende à ação - é removido pelo AGT, } \\
\text { o que permite que o AGO execute sua } \\
\text { tendência: roubar } R \$ 1 \text { bilhão. }\end{array}$ & $\begin{array}{l}\text { “[...] a polícia } \\
\text { permitiu que } \\
\text { quadrilha } \\
\text { roubasse R\$1 } \\
\text { bilhão” }\end{array}$ \\
\hline CONCESSÃO & $\begin{array}{l}\text { AGO: a quadrilha (que tende a roubar } R \$ 1 \text { bilhão) } \\
\text { ANT: a polícia } \\
\text { RES: roubar R\$ } 1 \text { bilhão } \\
\text { ANT, fraco e com tendência ao repouso, não } \\
\text { consegue impor-se sobre o AGo, mais forte e } \\
\text { com tendência ação - ainda que o confronte -, } \\
\text { de forma que a resultante continua sendo } \\
\text { roubar } R \$ 1 \text { bilhão. }\end{array}$ & $\begin{array}{c}\text { “[...] a despeito } \\
\text { da polícia, } \\
\text { quadrilha } \\
\text { roubou R\$1 } \\
\text { bilhão" }\end{array}$ \\
\hline AUXÍLIO & $\begin{array}{l}\text { AGO: a quadrilha (que tende a roubar } R \$ 1 \text { bilhão) } \\
\text { ANT: a polícia } \\
\text { RES: roubar R\$ } 1 \text { bilhão } \\
\text { ANT e AGO, ambos com tendência à ação, } \\
\text { juntam suas forças para causar a resultante } \\
\text { roubar } R \$ 1 \text { bilhão. }\end{array}$ & $\begin{array}{c}\text { “[...] a polícia } \\
\text { ajudou a } \\
\text { quadrilha a } \\
\text { roubar R\$1 } \\
\text { bilhão" }\end{array}$ \\
\hline
\end{tabular}

Fonte: Elaboração própria

A partir dessas premissas, podemos elaborar analogicamente uma tipologia de cinco Circunstâncias (logo, de estados-de-coisa presentes) que permita descrever e explicar, de modo mais detido, o funcionamento da argumentação prática" ${ }^{11}$ :

a) Circunstâncias Motivadoras: trata-se daquelas que dão origem ao problema prático, na medida em que resultam de um enquadramento discursivo que avalia o estado-de-coisas presente de forma negativa,

\footnotetext{
${ }^{10}$ Tal padrão não poderia ser concebido, da forma como expomos, a partir da concepção de Talmy (2000), que não prevê entidades de força atuando no mesmo sentido. Trata-se de uma elaboração que fazemos a partir da proposta de Wolff \& Thorstad (2017), que prevê tal tipo de interação.

${ }^{11}$ Ressaltamos, assim, a importância de compreender o Quadro 2 como uma exposição didática e sintética do funcionamento do esquema imagético de FORÇA a fim de que o leitor possa acompanhar o raciocínio que desenvolvemos a partir deste ponto do artigo, que estende tais concepções (AGO, ANT e AGT, por um lado, e CAUSAÇÃO, BLOQUEIO, PERMISSÃO, CONCESSÃO e AUXíLIO, por outro) ao processo argumentativo. Logo, não queremos com isso dar a impressão - de forma alguma - de que a análise dessas relações ocorrerá em termos de fronteiras sentenciais ou intersentenciais.
} 
mais especificamente, como indesejável, inaceitável ou, pelo menos, aprimorável. É sobre esse tipo de Circunstância que Fairclough \& Fairclough (2012) basicamente se detêm. Nesse caso, a situação negativa presente é tida como um AGo em repouso, que tende a se manter assim a não ser que haja uma intervenção. Tal intervenção consiste na Proposta de Ação, um ANT, que deve ser mais forte, no sentido de conseguir vencer a inércia do AGo e promover uma mudança na realidade de forma a alcançar um estado de mundo visado, expresso em termos de um Objetivo. No caso, a resultante da interação entre ANT e AGo seria a efetivação do estado-de-coisas futuro. Trata-se de uma aplicação argumentativa do padrão esquemático de CAUSAÇÃO;

b) Circunstâncias Viabilizadoras: consistem naquelas que delimitam a viabilidade da Proposta de Ação, indicando que há, no estado-decoisas presente, condições para aplicá-la. A análise desse tipo de Circunstância está ligada, como o próprio nome indica, à avaliação do critério de viabilidade da Proposta. No caso, a Proposta de Ação é concebida como um AGO em movimento que poderia estar sendo bloqueado por uma série de fatores (humanos, sociais, naturais, legais, dentre outros), que consistiriam em um ANT em repouso. As Circunstâncias Viabilizadoras atuariam, então, como AGTs responsáveis por desengajar o ANT, permitindo, assim, o fluxo do AGO. Muitas vezes, o debate sobre uma dada Proposta de Ação se concentra justamente nesse tipo de circunstância, avaliando-se em que medida o que se sugere é, de fato, factível. Elaboramos esse tipo de Circunstância a partir do padrão esquemático de DESENGAJAMENTO;

c) Circunstâncias Bloqueadoras: constituem-se naquelas que delimitam a inviabilidade da Proposta de Ação, indicando que não há, no estadode-coisas presente, condições para aplicá-la. Nesse sentido, elas podem direcionar a reflexão, em textos monologias, ou a deliberação, em textos dialogais sob contextos pragmaticamente relevantes, para a rejeição da Proposta em foco e para a ponderação de alguma Contra-Proposta de Ação. Nessa situação, a Proposta de Ação é tomada como um AGo em movimento, orientado à efetivar o estadode-coisas visado, e a situação presente é concebida como um ANT 
forte em repouso, capaz de bloquear a concretização da proposta, seja porque faltam recursos, seja porque infringem regras ou normas institucionais, por exemplo. De modo semelhante às Viabilizadoras, a análise desse tipo de Circunstância está associada ao critério da viabilidade da Proposta. O padrão esquemático que nos orientou na elaboração desta categoria é o de BLOQUEIO;

d) Circunstâncias Adversas: são aquelas que delimitam condições que desestimulam a realização da Proposta de Ação. Elas não são vistas como bloqueadoras, na medida em que não são construídas como impeditivas; contudo, oferecem obstáculos para a efetivação da Proposta. Em geral, elas tendem a atuar ou como um mecanismo de ponderação que requisitará dos oradores uma reavaliação do projeto ou como um mecanismo de atrição relativo à Proposta, buscando desestimular adesão, dadas as dificuldades de concretização, ainda que seja possível fazê-lo. Por conseguinte, elas também podem direcionar a deliberação para uma possível Contra-Proposta. Tal tipo circunstancial originou-se de uma analogia com o padrão esquemático de CONCESSÃo. Nesse caso, a Proposta é um AGo forte em movimento, e as Circunstâncias Adversas são um ANT fraco em repouso; em outros termos, elas atrapalham, mas não impedem a efetivação. O debate, portanto, é orientado quanto ao critério de eficiência, auferindo o quanto de esforço e de sacrifício será necessário para conseguir instanciar a Proposta, o que, em geral, nos leva a indagar se vale a pena;

e) Circunstâncias Catalisadoras: trata-se daquelas que delimitam o potencial de o estado-de-coisas presente apresentar condições que garantam o alcance do estado de mundo futuro expresso nos Objetivos, por meio da efetivação da Proposta de Ação. Assim, a análise desse tipo circunstancial consiste em um dos elementos que compõem tanto o critério da eficácia quanto da eficiência da Proposta. O padrão esquemático que dá origem a essa Circunstância é o de AUxílIO. No caso, ANT e AGo estão ambos orientados à mudança; a Proposta, o AGo, tem seu potencial de efetivar os Objetivos ampliado pelo ANT Catalisador. 
Antes de passarmos à aplicação do layout ao tweet da edutuber Nilce Morreto, julgamos ser relevante realizar duas ressalvas importantes:

a) o layout proposto não deve ser compreendido em termos normativos, ou seja, como um modelo ideal de como deve ser construído um movimento argumentativo orientado à resolução de um problema prático; pelo contrário: trata-se de um instrumento descritivo que permite ao analista depreender o papel das proposições, derivadas de enunciados, que convergem na defesa ou na refutação de uma Proposta de Ação;

b) os componentes do layout não necessitam ser todos instanciados para que possamos compreender um movimento argumentativo como prático. Certamente, é necessário que haja uma Proposta de Ação orientada um Objetivo, considerando uma leitura negativa do estado-de-coisas Presente, ou seja, do caráter indesejável, inaceitável ou aprimorável das Circunstâncias Motivadoras. É claro que, conforme já argumentamos, existem Valores que sustentam todos esses componentes, especialmente as Circunstâncias Motivadoras e os Objetivos; contudo, eles não necessariamente são explicitados na argumentação. O mesmo vale para as Consequências (Positivas ou Negativas) e para os diversos tipos de Circunstância. Em outros termos, uma Proposta de Ação pode ser defendida pela focalização de apenas um de seus eixos de funcionamento: eficácia, viabilidade, eficiência, inofensividade, beneficiação ou respeito aos Valores.

Isso posto, passamos à análise do texto selecionado.

4. A produtividade do layout de argumentação prática em textos monologais: análise de um tweet sequencial

A aplicação de nossa releitura do layout de Fairclough \& Fairclough (2012) para a análise da argumentação prática em textos monologais de visada argumentativa prática (AMOSSY, 2018) será realizada a partir de um tweet sequencial $^{12}$ publicado pela edutuber Nilce Moretto ${ }^{13}$ em 26 de janeiro de 2019.

\footnotetext{
${ }^{12}$ Denominamos tweet sequencial um encadeamento de tweets, publicados pelo usuário de forma conjunta e associada, o que possibilita romper com a limitação de caracteres da plataforma. Normalmente, tal conjunto possui uma centração tópica (JUBRAN, 2006) que lhe dá coerência.
} 
Nesse texto, a oradora tematiza a problemática contemporânea da crise da autoridade e da credibilidade dos especialistas, bem como da emergência do conservadorismo obscurantista que rejeita o intelectualismo e, com ele, o discurso científico, o discurso progressista, dentre outros. Transcrevemos, abaixo, a postagem:

\section{Quadro 2 - Tweet sequencial de Nilce Moretto (26 jan. 2019)}

\begin{tabular}{|c|l|}
\hline $\begin{array}{c}\text { Tweet 1 } \\
\text { (T1) }\end{array}$ & $\begin{array}{l}\text { Quero fazer um apelo a você que é especializado em áreas relacionadas a } \\
\text { ciência, meio ambiente, desenvolvimento sustentável. Venha pra internet, } \\
\text { abra um canal no Youtube, crie uma conta no twitter. Ocupe espaços. Há } \\
\text { muita carência de informação. }\end{array}$ \\
\hline $\begin{array}{c}\text { Tweet } 2 \\
\text { (T2) }\end{array}$ & $\begin{array}{l}\text { Os conspiracionistas, os mentirosos, os que inventam narrativa pra } \\
\text { acomodar ideologia agem com muita velocidade pq o trabalho deles é } \\
\text { simples, não precisam respaldar seus argumentos. Desmentir e confrontar } \\
\text { essa galera é um trabalho hercúleo, principalmente se não somos da área. }\end{array}$ \\
\hline $\begin{array}{c}\text { Tweet } 3 \\
(\text { T3 })\end{array}$ & $\begin{array}{l}\text { Se você tem bagagem, experiência, tem às mãos sua pesquisa, venha e } \\
\text { torne público! Um vídeo que alcance mil pessoas já alcançará muito mais } \\
\text { que a média de um artigo científico. Eu sei que pesa uma suspeita sobre a } \\
\text { internet, mas a credibilidade de uma plataforma se constrói. }\end{array}$ \\
\hline $\begin{array}{c}\text { Tweet } 4 \\
\text { (T4) }\end{array}$ & $\begin{array}{l}\text { Esse é um apelo mesmo. Tem gente cultuando a estupidez. A educação e a } \\
\text { ciência precisam ser valorizados. Precisamos de braços, de gente } \\
\text { comprometida com a dialética e não com as narrativas. Terei o prazer em } \\
\text { conhecer seu trabalho e apoia-lo e tenho certeza de que não serei só eu. }\end{array}$ \\
\hline
\end{tabular}

Fonte: https://twitter.com/nilmoretto/status/1089259617798897664

O texto constitui um exemplar típico de argumentação prática monologal, na medida em que ele é orientado a levar um determinado conjunto de atores sociais - no caso, especialistas em ciência, meio ambiente e desenvolvimento sustentável - a tomar uma decisão relativa a um fazer, ou seja, a um projeto de mudança de realidade que deve ser implementado para a transformação futura do estado-de-coisas negativo presente. Ademais, o foco do texto é defender uma dada Proposta de Ação para atingir esse futuro positivo - logo, estamos diante de uma argumentação que se debruça sobre

\footnotetext{
${ }^{13}$ Nilce Moretto é autora do canal Cadê a chave?, da plataforma digital YouTube, junto a seu marido, Leon Martins. O Cadê a Chave? conta atualmente (17 set. 2019) com 3,59 milhões de inscritos e congrega interessados em "cinema, diversão, viagens, novas tecnologias, relacionamento, histórias e em rir dos tombos da vida”, de acordo com a descrição contida na página do próprio canal. Fonte: https://www.youtube.com/user/cadeachave/about
} 
um problema prático orientado a alternativas de ação. Detalharemos, na sequência, como se dá a argumentação no tweet.

Em T1, a voz autoral constrói sua Proposta de Ação e inicia o processo de elaboração das Circunstâncias Motivadoras, ou seja, do delineamento do estado-de-coisas presente problemático. A Proposta de Ação é enunciada de forma a cobrir dois aspectos centrais de seu funcionamento: (i) a delimitação dos atores sociais que devem colocar em prática a Proposta; (ii) as ações que devem ser efetivadas para o alcance dos Objetivos, por ora não elaborados.

A delimitação do alvo da Proposta é realizada no primeiro complexo oracional: Quero fazer um apelo a você que é especializado em áreas relacionadas a ciência, meio ambiente, desenvolvimento sustentável. Simulando um diálogo direto com o possível agente de transformação, Nilce Moretto explicita que sua argumentação não se volta a qualquer ator social, mas a um tipo específico - um especialista, ou seja, alguém dotado de um saber profissional que será capaz de agir no sentido de levar ao estado-de-coisas futuro almejado. A delimitação dos atores envolvidos em uma Proposta de Ação é um aspecto essencial da argumentação prática, uma vez que, para ser implementada, ela deve responder ao critério de viabilidade; em outros termos, deve lidar com a questão de haver (ou não) recursos humanos, atores sociais avaliados como competentes para, de fato, efetivar o projeto de transformação e levá-lo a cabo. Por meio dessa construção, Moretto parece indicar sua filiação a um discurso que valoriza o intelectualismo, a academia e a ciência, posicionando-se, assim, em um dos polos da problemática contemporânea que apontamos no início da análise. Logo, a adesão desses atores sociais tornaria viável o alcance dos Objetivos.

A Proposta de Ação, por sua vez, é construída de forma complexa: por meio do uso do imperativo, elaboram-se duas Propostas genéricas complementares - vir para a internet e ocupar espaços -, que são, então, especificadas por duas alternativas concretas de ação - abrir um canal no YouTube, criar uma conta no Twitter. Tais alternativas não nos parecem, contudo, atuar no sentido de encerrar o rol de possibilidades, mas sim a de funcionar como exemplos válidos, com potencial de sucesso, para o alcance dos Objetivos. Certamente, outros seriam possíveis. 
Ainda que, por ora, os Objetivos não tenham sido enunciados e não saibamos, portanto, qual seria a necessidade do apelo, apenas o fato de esse elemento lexical ter sido enunciado já sinaliza que estamos diante de um problema que requisita intervenção. Tal problema, que representa as Circunstâncias Motivadoras da Proposta de Ação, é elaborado na última oração de T1 e em T2. Vejamos pormenorizadamente.

A última oração de T1 parece, de modo análogo ao que ocorre na elaboração da Proposta de Ação, atuar como uma proposição genérica que

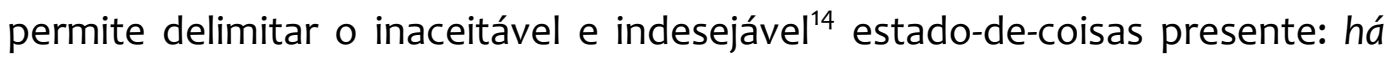
muita carência de informação. Essa carência parece, então, atuar - segundo a ótica do discurso da Proponente - como um fator que dá condições para a ação de atores sociais de comportamento condenável, conforme fica evidenciado no primeiro complexo oracional de T2: Os conspiracionistas, os mentirosos, os que inventam narrativa pra acomodar ideologia agem com muita velocidade pq o trabalho deles é simples, não precisam respaldar seus argumentos.

Nilce Moretto avalia esses atores sociais a partir do valor da desonestidade (MARTIN \& WHITE, 2005), destacando o comprometimento destes com a falsidade ou com a mentira, bem como com a desinformação e com a displicência no embasamento de suas posições. Resultaria dessa dinâmica a velocidade de elaboração dos seus textos e de suas postagens - e, com isso, é claro, a ocupação de muitos espaços com a repetição desenfreada de tais posicionamentos desonestos.

Por meio da contraposição entre a construção presente de um estado de carência de informação e a ação manipuladora de dados atores sociais, a voz autoral parece associar implicitamente o estado de informado à capacidade de resistir ao logro, como se aquele fosse uma espécie de imunizante. Nesse sentido, podemos depreender que os Objetivos consistem em alcançar um estado-de-coisas em que a população esteja informada e, assim, capaz de exercer senso crítico; logo, vemos que parte do trabalho de depreensão dos Objetivos, quando não explícitos, perpassa compreendermos o cerne das Circunstâncias Motivadoras.

14 Justificaremos a atribuição do estado-de-coisas presente como indesejável e inaceitável posteriormente. 
O complexo oracional final de T2 - Desmentir e confrontar essa galera é um trabalho hercúleo, principalmente se não somos da área - justifica o direcionamento do apelo aos especialistas pertinentes, argumentando a partir do critério da eficiência - no caso, o grau de esforço para a efetivação da Proposta, marcado textualmente pelo sintagma nominal um trabalho hercúleo. Nilce Moretto parece apontar para o fato de que, considerando a velocidade de atuação dos atores sociais de comportamento condenável, não ser especialista torna-se um fator que dificulta - e muito - o combate pari passu desse tipo de discurso, muito provavelmente porque o tempo de preparo dos vídeos seria muito mais longo, dada a necessidade de respaldo argumentativo - diferente do que supostamente ocorreria com o exogrupo. Logo, não ser especialista torna-se uma Circunstância Adversa, que subtrai eficiência da proposta. Tal ineficiência poderia, então, ser contornada pela ação concreta de atores sociais especializados nas temáticas pertinentes que já tivessem, conforme ela explicita em T3, bagagem, experiência e pesquisa em mãos. Esses três elementos são, pois, construídos como Circunstâncias Viabilizadoras da Proposta, atribuindo-lhe exequibilidade e eficiência.

T3 mantém, à semelhança de T1, um diálogo direto com os interlocutores que são alvo da Proposta de Ação, marcado pela segunda pessoa do singular (você) e pelo modo imperativo verbal: venha e torne público! Nesse momento, a edutuber esclarece de que forma os espaços virtuais devem ser ocupados diante da problemática em questão: as contas do Twitter e os canais do YouTube devem ser desenvolvidos para tornar públicas pesquisas científicas disponíveis - possivelmente, consolidadas. A partir disso, torna-se possível, então, inferir a relação Meio-Fim que sustenta a argumentação: Tornar públicas na internet as pesquisas desenvolvidas por especialistas levará a população a estar informada - com todo os benefícios decorrentes disso, como o já mencionado exercício de senso crítico.

Nesse sentido, o complexo oracional seguinte parece atuar como uma justificativa para o Meio-Fim, orientado, portanto, a dissolver possíveis ceticismos ou refutações que não concebessem a internet como um lugar com potencial para conduzir ao estado-de-coisas futuro almejado - Um vídeo que alcance mil pessoas já alcançará muito mais que a média de um artigo científico. Ao ressaltar o alcance das publicações digitais, a Proponente se vale da quantidade de acessos como estratégia de busca de adesão a sua Proposta e 
de estabelecimento de consistência para a sua argumentação, uma vez que o Objetivo de tornar a população informada perpassa maior acessibilidade às discussões científicas; logo, divulgar em canais de popularização, que exponencializam a distribuição de resultados, consiste em etapa importante nesse processo. Soma-se a isso o fato de a voz autoral dialogar com as práticas coercitivas da academia, que valorizam o alcance e o impacto das pesquisas como medida da qualidade e da relevância do trabalho desenvolvido. Nilce parece, assim, saber construir sua argumentação em face desse ator social visado.

Contudo, no último complexo oracional de T3, Nilce Moretto se vale de uma construção concessiva paratática - denominada, pela Norma Gramatical Brasileira, adversativa - para trazer um discurso de resistência ao seu posicionamento, ainda que de forma a contrair seu espaço de legitimidade, refutando-o. Vejamos o excerto: Eu sei que pesa uma suspeita sobre a internet, mas a credibilidade de uma plataforma se constrói.

A voz autoral dialoga com o discurso que concebe a internet como um espaço não ideal para a discussão ou o debate científico, como um espaço carente de credibilidade, ao qual se atribui responsabilidade, inclusive, por facilitar a emergência desses discursos anti-intelectualistas ou anticientíficos contra os quais a própria edutuber se volta. Reconhecer esse discurso - Eu sei - é uma estratégia retórico-discursiva relevante, na medida em que permite à voz autoral simular estar no lugar desse pesquisador ${ }^{15}$ que pode estar projetando a ineficácia desse empreendimento, ou seja, a dificuldade ou a impossibilidade de a Proposta de Ação realmente atingir os Objetivos, para, na sequência, refutar tal adversidade por alegar que a credibilidade de uma plataforma digital é resultado do trabalho de seus desenvolvedores, não sendo algo, portanto, estanque. Considerando que esse tipo de contrarefutação ${ }^{16}$ incide sobre o potencial de a Proposta de Ação gerar o estado-decoisas futuro estabelecido nos Objetivos, podemos compreender que se trata

\footnotetext{
15 Trata-se de uma estratégia discursiva empática (GONÇALVES-SEGUNDO \& RODRIGUES, 2016), ligada à dimensão analítica da ancoragem socioafetiva. Não entraremos em detalhes, uma vez que foge aos objetivos que propusemos para este trabalho.

${ }^{16}$ Falamos em contra-refutação, na medida em que a proposição de que a credibilidade de uma plataforma se constrói orienta-se a refutar a proposição de que pesa uma suspeita sobre a internet. Essa, por sua vez, poderia atuar como uma refutação para a argumentação desenvolvida, questionando a eficácia da atuação de especialista na rede para alcançar os Objetivos.
} 
de uma projeção de Circunstância Catalisadora. Circunstâncias Catalisadoras consistem em estados-de-coisa que aceleram o alcance dos Objetivos. Utilizamos o termo 'projeção', na medida em que Nilce não constrói a credibilidade como uma propriedade do presente, mas como um atributo que pode ser alcançado mediante trabalho na plataforma; assim que atingido, a catálise passa a operar. Isso posto, podemos entender esse complexo oracional final de T3 como uma estratégia de desestimular uma atitude cética à eficácia da Proposta de Ação.

T4 consolida o movimento argumentativo, (i) complementando as Circunstâncias Motivadoras - tem gente cultuando a estupidez; (ii) expandindo as Circunstâncias Catalisadoras, em um processo que se calca tanto no sucesso e na credibilidade de Nilce Moretto como produtora do Canal Coisa de Nerd, o que faz dela uma das edutubers mais relevantes do país, quanto do seu apoio, que configura um instrumento para legitimação e ampliação do potencial de distribuição do conteúdo de um novo canal ou conta - Terei o prazer em conhecer seu trabalho e apoia-lo [sic] e tenho certeza de que não serei só eu; (iii) explicitando os Valores a partir de duas formas distintas: em primeiro lugar, pela especificação do tipo de atitude esperada do pesquisadoralvo - gente comprometida com a dialética e não com as narrativas - e, em segundo lugar, pela elaboração daquilo que a edutuber acredita que precisa ser valorizado positivamente no país - a educação e a ciência. Tais Valores ecoam a filiação discursiva autoral que já podia ser inferida desde o tweet inicial, novamente demarcando seu posicionamento na problemática vigente e no dissenso acerca do papel da intelectualidade e da ciência como lentes legítimas para a interpretação dos processos e dos fenômenos naturais, sociais, psíquicos ou semióticos.

Com isso, conseguimos compreender por que o estado-de-coisas presente é construído, implicitamente, como inaceitável e indesejável: inaceitável, dado que resulta de uma necessidade de valorização da dialética, da educação e da ciência, em detrimento das narrativas ideologicamente enviesadas, das mentiras e das conspirações que a voz autoral assume como características do presente no qual predomina a carência de informação - com suas consequências potencialmente nefastas e já observáveis em nossa vida 
cotidiana $^{17}$; e indesejável, porque a voz autoral se constrói como fiadora desse propósito, como alguém que se coloca numa posição de apelo e que se compromete, pessoalmente, em catalisar o processo de ampliação das vozes resistentes, o que colabora para a construção de um ethos engajado, marcado pela vontade de causar mudança nas práticas e na estrutura social.

\section{Considerações finais}

Nosso objetivo, neste artigo, foi debater o layout de argumentação prática de Fairclough \& Fairclough (2012), mostrando seu potencial de aplicação a textos e interações que excedem práticas deliberativas políticas, foco da abordagem dos referidos autores, e discutindo possibilidades de ampliação, rearranjo e revisão de componentes, com o objetivo de refinar seu potencial descritivo e explicativo.

Em primeiro lugar, expusemos as principais premissas do modelo multidimensional de análise argumentativa que temos desenvolvido e situamos o mencionado layout, primariamente, no âmbito da configuração funcional e, secundariamente, na macroestrutura, considerando a intensa sobreposição entre tais dimensões no que tange à descrição da argumentação, em especial, de aspectos concernentes à sua consistência.

Em segundo lugar, apresentamos a proposta de Fairclough \& Fairclough (2012), alocando-a na discussão sobre dissenso e questão argumentativa, conforme a tradição francesa (Plantin, 2008; Grácio, 2010). A partir disso, conceptualizamos o layout de argumentação prática como um instrumento de análise de movimentos argumentativos orientados a responder um problema prático, sejam aqueles orientados a alternativas de ação ("O que deve ser feito para alcançar os Objetivos?"), sejam os orientados às motivações para ação ("Tal Proposta de Ação deve ou não ser efetivada?"). Posteriormente, discutimos, de forma a equilibrar, teórica e metodologicamente, os aspectos justificatório e retórico da atividade argumentativa, cada um dos componentes do layout: Proposta de Ação, Meio-Fim, Objetivos, Circunstâncias, Valores e Consequências Positivas e Negativas. No que tange às Circunstâncias, buscamos um diálogo com o referencial linguístico-cognitivo

${ }^{17}$ Nesse ponto, tomo a liberdade de extrapolar o texto analisado e assumir meu papel crítico diante da problemática discutida pela edutuber. 
e o esquema imagético de FORÇA, a fim de gerar uma tipologia mais refinada referente aos diferentes aspectos do estado-de-coisas presente, ressaltando sua importância para a compreensão da dinâmica de construção da consistência e da adesão a Propostas de Ação. Por conseguinte, propusemos as seguintes categorias: Circunstâncias Motivadoras, Viabilizadoras, Bloqueadoras, Adversas e Catalisadoras. Ademais, debatemos - organizando, sistematizando e ampliando propostas encontradas tanto em Fairclough \& Fairclough (2012), quanto em Walton \& Macagno $(2019)^{18}$ - uma série de seis critérios relevantes que permitem caracterizar o dissenso que cerca a tomada de decisão intrínseca à argumentação prática: trata-se dos critérios de eficácia, de viabilidade, de eficiência, de inofensividade, de beneficiamento e de respeito aos Valores.

Por fim, aplicamos essa releitura do layout de configuração da argumentação prática a um tweet sequencial da edutuber Nilce Moretto, de forma a mostrar seu potencial descritivo e explicativo para a análise de textos de visada argumentativa prática.

Uma próxima etapa de pesquisa importante consiste no exame da pertinência do que discutimos a outras práticas discursivas, tanto monologais quanto dialogais, em distintas esferas e gêneros discursivos, processo que pode levar a uma depuração cada vez maior do funcionamento do layout e da caracterização de cada um dos seus componentes. Uma etapa ulterior diz respeito à elaboração de módulos didáticos voltados ao trabalho com argumentação prática no Ensino Básico.

\section{Referências}

AMOSSY, Ruth. A argumentação no discurso. Coordenação da tradução: Eduardo Lopes Piris e Moisés Olímpio Ferreira. São Paulo: Contexto, 2018.

BERMEJO-LUQUE, Lilian. Giving Reasons: A Linguistic-Pragmatic Approach to Argumentation Theory. Heidelberg/New York/Dordrecht/London: Springer, 2011.

\footnotetext{
${ }^{18}$ Ressaltamos que tais critérios não devem ser entendidos de forma análoga a perguntas críticas, ainda que possam servir para embasá-las.
} 
FAIRCLOUGH, Isabela; FAIRCLOUGH, Norman. Political Discourse Analysis. A Method for Advanced Students. Londres; Nova York: Routledge, 2012

FAIRCLOUGH, Norman. Analysing discourse: textual analysis for social research. London, England: Routledge, 2003.

FREEMAN, James. Argument structure: Representation and theory. Dordrecht/Heidelberg/London/New York: Springer, 2011.

GONÇALVES-SEGUNDO, Paulo Roberto. A permeabilidade da Dinâmica de Forças: da gramática ao discurso. In: LIMA-HERNANDES, Maria Célia; RESENDE, Briseida Dôgo; DE PAULA, Fraulein Vidigal; MÓDOLO, Marcelo; CAETANO, Sheila Cavalcante (org.). Linguagem e cognição: Um diálogo interdisciplinar. Lecce: Pensa Multimedia Editores, 2015. p. 163-185.

. Argumentação e falácias em entrevistas televisivas: por um diálogo entre o modelo Toulmin e a perspectiva textual-interativa. Revista Linha D'Água, v. 29, n. 2, p. 69-96, 2016. DOI 10.11606/issn.2236-4242.v29i2p69-96

. Orientação argumentativa e cognição: A dinâmica de forças no debate acerca dos rolezinhos. Signo, n. 42, v. 73, p. 200-212, 2017a. DOI 10.17058/signo.v42i73.7924

- A relevância da noção de perspectivação conceptual (construal) no âmbito dos estudos do texto e do discurso: Teoria e análise. Letras, n. 27, v. 54, p. 69-100, 2017b. DOI 10.5902/2176148529571

. Argumentação e perspectivação conceptual: possibilidades teórico-analíticas. In: IV SEMINÁRIO INTERNACIONAL DE ESTUDOS SOBRE DISCURSO E ARGUMENTAÇÃO (SEDiAr), 4, 2018, Buenos Aires, Anais [...]. Ilhéus: Editus, 2018. p. 922-934. Disponível em: http://sediar.com/pdf/ActasIVSEDiAr.pdf.pdf

- The Multidimensional Model of Argumentative Analysis: An Introduction. Alfa: Revista de Linguística. (no prelo).

GONÇALVES-SEGUNDO, Paulo Roberto; RIBEIRO, Rafaela Baracat. Envolvimento e empatia: a solidariedade construída nas colunas de aconselhamento em revistas. Revista do GEL, v. 13, n. 2, p. 211-236, 2016. DOI 10.21165/gel.v13i2.835

GRACIO, Rui Alexandre. Para uma teoria geral da argumentação: questões teóricas e aplicações didácticas. 2010. Tese (Doutorado em Ciências da Comunicação) - Instituto de Ciências Sociais, Universidade do Minho, Braga, 2010.

HALLIDAY, Michael Alexander Kirkwood. Introduction to functional grammar. 3.ed. Revisão: Christian Matthiessen. London: Hodder Arnold, 2004.

HART, Christopher. Discourse, grammar and ideology: Functional and cognitive perspectives. London: Bloomsbury, 2014. 
JOHNSON, Ralph H.; BLAIR, John. Anthony. Lógica informal: uma visão geral. Tradução: Paulo Roberto Gonçalves-Segundo et al. EID\&A - Revista Eletrônica de Estudos Integrados em Discurso e Argumentação, Ilhéus, n. 14, p. 195-215, jul/dez. 2017.

JUBRAN, Clélia. Revisitando a noção de tópico discursivo. Caderno de Estudos Linguísticos, Campinas, n. 48, v. 1, p. 33-41, 2006.

LANGACKER, Ronald. Cognitive Grammar: a basic introduction. Oxford: Oxford University Press, 2008.

LANGSDORF, Lenore. Argumentation as contextual logic: An appreciation of backing in Toulmin's model. Cogency, n. 3, v. 2, p. 51-78, 2011. Disponível em: https://dialnet.unirioja.es/servlet/articulo?codigo=3963390

LEITÃO, Selma. O trabalho com argumentação em ambientes de ensinoaprendizagem: um desafio persistente. Uni-pluri/versidad, n. 12, v. 3, p. 23-37, 2012. Disponível em: encurtador.com.br/pr347

MACAGNO, Fabrizio; WALTON, Douglas. Argumentos de raciocínio prático: uma abordagem modular. Tradução: Paulo Roberto Gonçalves-Segundo, Gabriel IsolaLanzoni, Lucas Pereira da Silva e Winola Weiss Pires Cunha. EID\&A - Revista Eletrônica de Estudos Integrados em Discurso e Argumentação, Ilhéus, n. 19, p. 140184, ago.2019. DOI 10.17648/eidea-19-2448

MAINGUENEAU, Dominique. Ethos, cenografia, incorporação. In: AMOSSY, Ruth (org.). Imagens de si no discurso: a construção do ethos. São Paulo: Contexto, 2005. p. 69-92.

MARTIN, James; WHITE, Peter. The language of evaluation: appraisal in English. New York/Hampshire: Palgrave Macmillan, 2005.

MATEUS, Elaine; RESENDE, Viviane de Melo. O sistema posição-prática como categoria epistemológica: contribuições para análise de discurso crítica. Alfa: Revista de Linguística, v. 59, n. 3, p. 445-469, 2015. DOI 10.1590/1981-5794-1509-1

NIÑO, Douglas; MARRERO, Danny. The agentive approach to argumentation: a proposal. In: Van EEMEREN, Frans; GARSSEN, Bart (org.) Reflections on theoretical issues in argumentation theory. Heidelberg; New York; Dordrecht; London: Springer, 2015. p. 53-67.

OAKLEY, Todd. Force-dynamics dimensions of rhetorical effect. In: HAMPE, Beate; GRADY, Joseph (org.) From perception to meaning: image schemas in Cognitive Linguistics. Berlin: Mouton de Gruyter, 2005. 
PERELMAN, Chaïm; OLBRECHTS-TYTECA, Lucie. Tratado da argumentação: a nova retórica. Tradução: Maria Ermantina de Almeida Prado Galvão. São Paulo: Martins Fontes, 2002 [1958].

PLANTIN, Christian. A argumentação: história, teoria, perspectivas. Tradução: Marcos Marcionilo. São Paulo, Parábola, 2008.

SLOB, Wouter $\mathrm{H}$. The voice of the other: A dialogico-rhetorical understanding of opponent and of Toulmin's rebuttal. In: HITCHCOCK, David; VERHEIJ, Bart (org.). Arguing on the Toulmin model. New essays in argument analysis and evaluation. Dordrecht: Springer, 2006. p. 165-180.

SOUSA, Douglas Rabelo de. Argumentação, cognição e discurso: a polêmica entre conservadores e liberais sobre a imigração para o Brasil. 2018. Dissertação (Mestrado em Filologia e Língua Portuguesa) - Faculdade de Filosofia, Letras e Ciências Humanas, Universidade de São Paulo, São Paulo, 2018. DOI 10.11606/D.8.2019.tde15032019-122453

TOULMIN, Stephen. Os usos do argumento. 2.ed. São Paulo: Martins Fontes, 2006 [1958].

TOULMIN, Stephen; RIEKE, Richard; JANIK, Allan. An introduction to reasoning. 2'ed. New York: Macmillan Publishing Company, 1984 [1978].

Van EEMEREN, Frans H. Argumentation Theory: A Pragma-Dialectical Perspective. Cham: Springer, 2018.

VAN EEMEREN, Frans; HOUTLOSSER, Peter; SNOECK HENKEMANS, A. Francisca. Argumentative indicators in discourse: A pragma-dialectical study. Dordrecht: Springer, 2007.

VERHEIJ, Bart. Evaluating arguments based on Toulmin's scheme. In: HITCHCOCK, David; VERHEIJ, Bart (org.). Arguing on the Toulmin model. New essays in argument analysis and evaluation. Dordrecht: Springer, 2006. p. 181-202.

WALTON, Douglas. Practical reasoning. Savage: Rowman and Littlefield, 1990.

. Methods of Argumentation. New York: Cambridge University Press, 2013.

WALTON, Douglas; REED, Chris; MACAGNO, Fabrizio. Argumentation schemes. New York: Cambridge University Press, 2008.

WOLFF, Phillip; THORSTAD, Robert. Force Dynamics. In: WALDMANN, Michael R. (org.). The Oxford Handbook of Causal Reasoning. Oxford: Oxford University Press, 2017.

TALMY, Leonard. Towards a cognitive semantics. Cambridge: MIT Press, 2000. 


\section{Forma de citação sugerida}

GONÇALVES-SEGUNDO, Paulo Roberto. A configuração funcional da argumentação prática: uma releitura do layout de Fairclough \& Fairclough (2012). EID\&A - Revista Eletrônica de Estudos Integrados em Discurso e Argumentação, Ilhéus, n. 19, v. 2, p. 109-137, dez.2019. DOI 10.17648/eidea-19-v2-2498. 